\title{
Prevalence of Mental Disorders in Primary Care
}

\author{
Implications for Screening
}

Andrew C. Leon, PhD; Mark Olfson, MD; W. Eugene Broadhead, MD, PhD; James E. Barrett, MD; Robert S. Blacklow, MD; Martin B. Keller, MD; Edmund S. Higgins, MD; Myrna M. Weissman, PhD

Objectives: To determine the prevalence of five mental disorders in primary care and to identify patient groups that have a relatively high prevalence of these disorders.

Design: Two-stage case identification design that involves administration of a 16-item screening instrument followed by an independent diagnostic assessment.

Setting: Three family practice offices in Rhode Island.

Subjects: A total of 937 primary care patients completed the brief screen, 388 of whom completed the independent diagnostic assessment.

Prevalence Estimation: A Bayesian procedure was used to estimate prevalence of mental disorder from screening and assessment results. Independent assessments were based on the Structured Clinical Interview for DSM$I I I-R$ administered by a mental health professional.

Results: The prevalence estimates were alcohol abuse or dependence, $3.2 \%$; generalized anxiety disorder, $2.8 \%$; major depressive disorder, $14.1 \%$; obsessivecompulsive disorder, $2.2 \%$; panic disorder, $6.2 \%$; and any of the five disorders, $22.0 \%$. The prevalence of any of the five disorders was higher in patients returning for follow-up visits $(27.9 \%)$ than in those either presenting with a new illness $(21.7 \%)$ or seeking a routine physical examination (11.8\%). The combined prevalence was also higher in patients with a chronic medical problem $(25.8 \%)$ than in those without $(16.7 \%)$.

Conclusions: Patients returning for follow-up care and, to a lesser extent, those with chronic medical problems appear to be at increased risk of having a mental disorder. The practice of selectively screening new patients for mental health problems is questioned. Screening efforts in primary care should include established patients and those with chronic medical illnesses as well as new patients.

(Arch Fam Med. 1995;4:857-861)
From Cornell University Medical College, New York, NY (Dr Leon); College of Physicians and Surgeons of Columbia University and New York State Psychiatric Institute, New York (Drs Olfson and Weissman); Duke University Medical Center, Durham, NC, and Ambulatory Services of Danville (Va) (Dr Broadhead); Dartmouth Medical School, Hanover, NH (Dr Barrett); Northeastern Ohio Universities College of Medicine, Rootstown (Dr Blacklow); Brown University School of Medicine, Providence, RI (Dr Keller); and the Medical University of South Carolina, Charleston (Dr Higgins). Drs Leon, Olfson, Barrett, Blacklow, Keller, Higgins, and Weissman have served as consultants to The Upjohn Company, Kalamazoo, Mich.

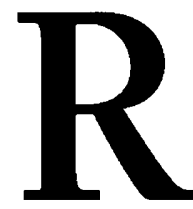

ESEARCHERS, clinicians, and policy makers all seek a better understanding of the amount, type, variety, and distribution of mental disorders in primary care. Accumulating evidence suggests that mental disorders are highly prevalent in primary care $e^{1-9}$ and commonly escape the detection of primary care physicians. ${ }^{10,11}$ In response to these findings, public health initiatives have been developed to help improve the recognition and treatment of mental disorder in primary care. ${ }^{12,13}$ Basic epidemiologic research has the potential to facilitate these initiatives by defining the prevalence of specific mental disorders in primary care and by identifying patient groups at an increased risk for specific mental disorders.

The administration of structured psychiatric interviews to representative samples of primary care patients provides a means of estimating the prevalence of specific mental disorders in pri- mary care populations. Systematic diagnostic interview assessments, such as the Schedule for Affective Disorders and Schizophrenia, ${ }^{14}$ the Diagnostic Interview Schedule, ${ }^{15}$ and the Structured Clinical Interview for Diagnostic and Statistical Manual of Mental Disorders, Revised Third Edition (DSM-III-R) (Patient Edition) (SCID-P),${ }^{16.17}$ permit determinations of the presence or absence of specific mental disorders based on welldefined criteria. Because of the long length of these interviews and the low expected prevalence of individual mental disorders in unselected primary care samples, . researchers have generally relied on twostage case identification procedures for prevalence estimates. All previous relevant studies known to us have applied this

See Subjects and Methods on next page 


\section{SUBJECTS AND METHODS}

\author{
SUBJECTS
}

The data are from the Symptom-Driven Diagnostic System for Primary Care (SDDS-PC) (trademark of The Upjohn Co, Kalamazoo, Mich) Validation Study, ${ }^{19}$ which was conducted in 1992 at three private family practice offices in cooperation with the Brown University (Providence, RI) Departments of Psychiatry and Family Medicine. The practices, which consist of six full-time and one part-time board-certified family physicians and two nurse practitioners, serve patients from Rhode Island and Massachusetts. All patients who were 18 through 70 years of age and provided informed consent were eligible to participate in the study.

\section{ASSESSMENT PROCEDURES}

A two-stage sampling design was used in which consenting subjects were given the SDDS-PC screen for multiple disorders in primary care. A subset of patients in the screen sample agreed to participate in a SCID-P interview. All interviewers were provided extensive SCID-P training and were blinded to the screen results.

The SDDS-PC screen, which consists of 16 items, includes subscales for the presence of five mental disorders and suicidal ideation in the past 30 days. The disorders include major depressive disorder, generalized anxiety disorder, obsessive-compulsive disorder, panic disorder, and alcohol abuse or dependence. These disorders were selected because of the empirical evidence of treatment efficacy. The development and validation of the SDDS-PC screen is fully described elsewhere. ${ }^{19}$ The SCID-P, which was used as the diagnostic standard for DSM-III-R diag- noses, was developed by Michael First, MD, for the DSM-IV field trials. ${ }^{20}$

\section{STATISTICAL PROCEDURES}

The demographic characteristics of the samples that did and did not receive the SCID-P were compared using $\chi^{2}$ tests for categorical variables and $t$ tests for continuous variables. All tests were two tailed with $\alpha=.05$.

The procedure that was used for prevalence estimation is based on the methods for a prospective sampling design that is described in detail by Kraemer. ${ }^{21}$ By definition, prevalence is equal to the sum of the number of true-positive (TP) and the number of false-negative (FN) results divided by the total number of subjects assessed. However, because only a subset $(n=388)$ of those screened $(n=937)$ actually received the full diagnostic assessment (the SCID-P), Bayesian procedures must be used to estimate TP and $F N$ rates in the screened sample. Each estimate is based on the screen positive rate $(Q)$ of the sample that received the screen and the positive predictive value (PPV) and negative predictive value (NPV) of the sample that received both the screen and the SCID-P. Where TP is the product of Q and PPV, $F N$ is the product of $(1-Q)$ and $(1-N P V)$. Therefore, the prevalence $(P)$ is computed as the sum of the estimates of TP and FN: $P=(Q \times P P V)+[(1-Q)(1-N P V)]$.

Stratified rates were also estimated. Stratification variables include gender, reason for visit (the patient indicated whether the visit was for a routine physical examination, a new illness, or a follow-up), and chronic medical problem (the physician was systematically asked whether the patient presented with a chronic medical problem). Stratification analyses included only those subjects with necessary stratification data. Rates are presented with $95 \%$ confidence intervals. strategy by using a brief screening instrument followed by selective administration of a more extensive diagnostic interview.

Hoeper and colleagues ${ }^{10}$ were the first to estimate the prevalence of specific mental disorders in a primary care practice. Their study, which was conducted in Marshfield, Wis, concluded that the overall prevalence of Research Diagnostic Criteria (RDC) ${ }^{18}$ mental disorders was $26.7 \%$, with major depression (5.8\%) and phobic disorder $(5.8 \%)$ as the two most prevalent disorders. ${ }^{10}$ Schulberg and coworkers ${ }^{5}$ subsequently determined that $9.2 \%$ of an adult sample presenting to three primary care clinics in the Pittsburgh, Pa, area met DSM-III criteria for depression (major depressive episode, bipolar II disorder, dysthymia, or adjustment disorder with depressed mood). Other common disorders in that study included alcohol abuse $(8.2 \%)$, substance abuse $(7.1 \%)$, phobia $(6.8 \%)$, and antisocial personality disorder $(5.8 \%)$.

Von Korff and coworkers ${ }^{6}$ estimated that $25 \%$ of an urban primary care sample met criteria for at least one of nine DSM-III disorders: major depression ( $5.0 \%$ ), dysthymia $(3.7 \%)$, panic disorder $(1.4 \%)$, generalized anxiety disorder $(4.6 \%)$, obsessive-compulsive disorder $(1.1 \%)$, cognitive impairment $(7.8 \%)$, alcohol abuse or dependence $(5.0 \%)$, schizophrenia (0.4\%), and phobias $(7.8 \%)$.
Barrett and colleagues ${ }^{7}$ reported that the prevalence of RDC diagnoses was $26.5 \%$ in patients in a primary care practice in Hanover, $\mathrm{NH}$. In their sample, $10.0 \%$ of the patients met criteria for one of the specific depressive disorders, $5.3 \%$ were classified as having a mental disorder without depression, and an additional $11.2 \%$ were classified as having significant depressive symptoms but not a specific depressive disorder.

Blacker and Clare ${ }^{8}$ found an overall prevalence of psychiatric disorder of $35.3 \%$ among consecutive patients in an inner-city general health center in London, England. The most common disorders were stress/ adjustment (17.9\%), RDC minor depressive disorder (5.7\%), RDC major depressive disorder (4.3\%), and anxiety disorders (3.2\%) including anxiety neurosis, panic disorder, and phobic disorder. Alcoholism (2.6\%), major personality disorder $(2.6 \%)$, schizophrenia and related psychotic disorders (2.6\%), drug dependence (1.2\%), and bipolar disorder $(0.9 \%)$ were all less common.

The present study applied a two-stage diagnostic procedure to consenting adult patients at three family practices in Rhode Island. A screening instrument was administered, followed by the SCID-P modified for primary care. Prevalence estimates are presented for five DSMIII-R disorders (major depression, panic disorder, gen- 
eralized anxiety disorder, obsessive-compulsive disorder, and alcohol abuse or dependence). The relationships between selected clinical variables and specific mental disorders are examined.

\section{RESULTS}

The recruitment of patients proceeded in the following manner. A total of 1340 patients were invited to partici-

\begin{tabular}{|c|c|c|c|c|c|}
\hline & $\begin{array}{l}\text { Received } \\
\text { SCID-P* }\end{array}$ & $\begin{array}{l}\text { Did Not } \\
\text { Receive } \\
\text { SCID-P }\end{array}$ & $x^{2}$ & $d f$ & $P$ \\
\hline Gender, No. (\%) & & & 0.32 & 1 & .57 \\
\hline M & $105(27.1)$ & $159(29.0)$ & & & \\
\hline $\mathrm{F}$ & $283(72.9)$ & $390(71.0)$ & & & \\
\hline Race, No. $(\%)$ & & & 4.25 & 2 & .12 \\
\hline W & $380(97.9)$ & $530(97.4)$ & & & \\
\hline B & $1(0.3)$ & $8(1.5)$ & & & \\
\hline Other & $7(1.8)$ & $6(1.2)$ & & & \\
\hline Marital status, No. $(\%)$ & & & 12.9 & 4 & .01 \\
\hline Married & $246(64.4)$ & $297(54.6)$ & & & \\
\hline $\begin{array}{l}\text { Living with } \\
\text { someone }\end{array}$ & $20(5.2)$ & $48(8.8)$ & & & \\
\hline Widowed & $11(2.9)$ & $18(3.3)$ & & & \\
\hline $\begin{array}{l}\text { Separated } \\
\text { or divorced } \\
\text { Never married }\end{array}$ & $\begin{array}{l}34(8.9) \\
71(18.6)\end{array}$ & $\begin{array}{c}42(7.7) \\
139(25.6)\end{array}$ & & & \\
\hline Education, No. (\%) & & & 5.65 & 3 & .13 \\
\hline$<9$ th grade & $6(1.6)$ & $14(2.6)$ & & & \\
\hline High school & $106(27.7)$ & $178(33.1)$ & & & \\
\hline Some college & 94 (24.6) & $134(25.0)$ & & & \\
\hline Graduated college & $176(46.1)$ & $211(39.3)$ & & & \\
\hline Age, y, mean (SD) & $39.4(12.4)$ & $37.8(13.7)$ & $t=-1.84$ & 881.6 & .07 \\
\hline
\end{tabular}

*SCID-P indicates Structured Clinical Interview for the Diagnostic and Statistical Manual of Mental Disorders, Revised Third Edition (Patient Edition). pate in the study. Nine hundred thirty-seven subjects $(70 \%)$ were screened. Of the screened sample, $388(41 \%)$ received the SCID-P. The sample had a mean age of 38.4 years $(\mathrm{SD}=13.2)$ and was primarily female $(71.8 \%)$, white (97.6\%), married (58.6\%), and well educated $(66.9 \%$ had at least some college). For the most part, the demographic characteristics of those who did and did not receive the SCID-P are similar (Table 1). However, a slightly higher, yet significantly different, proportion of the sample that received the SCID-P were married (64.4\% of those who received the SCID-P vs $54.6 \%$ of those who did not).

The 1-month prevalence estimates are as follows: alcohol abuse or dependence, $3.2 \%$; generalized anxiety disorder, $2.8 \%$; major depressive disorder, $14.1 \%$; obsessivecompulsive disorder, $2.2 \%$; panic disorder, $6.2 \%$; and any of the five disorders, $22.0 \%$. These rates were also stratified by gender (Table 2). Women had approximately a twofold elevation in rates of major depressive disorder, obsessive-compulsive disorder, and panic disorder. Men had higher rates of alcohol abuse or dependence.

Rates of mental disorders were also stratified by the reason for the visit (Table 3). The patient was asked if the visit was for a new illness $(n=248,30 \%$ of the 828 who provided this information), a follow-up ( $n=263$, $31.7 \%)$, or a routine physical examination $(n=317,38.3 \%)$. The rates of each mental disorder were considerably lower for those who were presenting for a routine physical examination (eg, $11.8 \%$ had at least one disorder). The patients were also classified on the basis of the physician's report of the chronicity of the medical problem. Half of the patients were classified as having a chronic medical problem $(n=415,50.6 \%$ of the 820 with chronicity information). The patients presenting with chronic medical problems had elevated rates of major depressive disorder (chronic problem, 16.0\%; no chronic problem,

Table 2. Prevalence of Psychiatric Disorders

\begin{tabular}{|c|c|c|c|}
\hline \multirow[b]{2}{*}{ Diagnosis } & \multicolumn{3}{|c|}{ Rates/100 (95\% Confidence Interval) } \\
\hline & Men & Women & Total \\
\hline Alcohol abuse or dependence & $7.6(4.5$ to 10.7$)$ & $1.7(0.7$ to 2.7$)$ & 3.2. $(2.0$ to 4.4$)$ \\
\hline Generalized anxiety disorder & $0.0(0.0$ to 0.0$)$ & $3.9(2.5$ to 5.3$)$ & $2.8(1.8$ to 3.8$)$ \\
\hline Major depression & $7.5(4.4$ to 10.6$)$ & $16.5(13.8$ to 19.2$)$ & 14.1 (11.9 to 16.3$)$ \\
\hline Obsessive-compulsive disorder & $0.9(-0.3$ to 2.1$)$ & $2.7(1.5$ to 3.9$)$ & $2.2(1.2$ to 3.2$)$ \\
\hline Panic disorder & $4.0(1.6$ to 6.4$)$ & 7.1 (5.1 to 9.1$)$ & $6.2(4.6$ to 7.8$)$ \\
\hline Any of the above & $14.5(10.2$ to 18.8$)$ & 24.9 (21.6 to 28.2$)$ & $22.0(19.3$ to 24.7$)$ \\
\hline
\end{tabular}

Table 3. Prevalence of Psychiatric Disorders Stratified by Patient's Reason for Visit to Physician

\begin{tabular}{lccc}
\hline \multicolumn{1}{c}{} & \multicolumn{2}{c}{ Rates/100 (95\% Confidence Interval) } \\
\cline { 2 - 3 } Diagnosis & New Illness & Follow-up & \multicolumn{1}{c}{$\begin{array}{c}\text { Routine Physical } \\
\text { Examination }\end{array}$} \\
\hline Alcohol abuse or dependence & $1.2(-0.2$ to 2.6$)$ & $7.4(4.3$ to 10.5$)$ & $0.9(-0.1$ to 1.9$)$ \\
Generalized anxiety disorder & $2.7(0.7$ to 4.7$)$ & $4.5(2.0$ to 7.0$)$ & $1.5(0.1$ to 2.9$)$ \\
Major depression & $15.7(11.2$ to 20.2$)$ & $16.9(12.4$ to 21.4$)$ & $5.0(2.6$ to 7.4$)$ \\
Obsessive-compulsive disorder & $1.8(0.2$ to 3.4$)$ & $0.8(-0.4$ to 2.0$)$ & $1.6(0.2$ to 3.0$)$ \\
Panic disorder & $5.6(2.7$ to 8.5$)$ & $8.3(5.0$ to 11.6$)$ & $2.8(1.0$ to 4.6$)$ \\
Any of the above & $21.7(16.6$ to 26.8$)$ & $27.9(22.4$ to 33.4$)$ & $11.8(8.3$ to 15.3$)$ \\
\end{tabular}


$11.2 \%$ ) and panic disorder (chronic problem, 7.8\%; no chronic problem, 4.0\%) (Table 4).

\section{COMMENT}

Our results are broadly consistent with previous research on the measurement of mental disorders in primary care. In accord with earlier studies, we found that major depression was the most common mental disorder in primary care practice ${ }^{7,22}$ and that rates of mental disorders tended to be elevated among women.,23,24

At the level of individual disorders, our prevalence estimates tended to be somewhat higher than previously reported figures (Toble 5). In particular, our estimate that $14.1 \%$ of primary care patients meet criteria for major depression is well above previously published findings ( $2.8 \%$ to $9.2 \%$ ). In contrast, our estimates for the prevalence of generalized anxiety disorder $(2.8 \%)$ and alcohol abuse or dependence (3.2\%) fall between previously published estimates of $1.6 \%$ to $11.9 \%$ and $2.6 \%$ to $5.0 \%$, respectively. However, we also present higher rates of panic disorder $(6.2 \%$ vs $1.4 \%$ to $4.3 \%$ ) and obsessive-compulsive disorder ( $2.2 \%$ vs $0.7 \%$ to $1.2 \%$ ) than have been previously reported in primary care. The extent to which these differences are attributable to actual differences in patient populations rather than differences in survey methods remains unknown.

The rates that we found in primary care are, for the most part, elevated relative to the general population. For instance, in the Epidemiologic Catchment Area Program ${ }^{23}$ 1 -month prevalence rates were as follows: alcohol abuse

Table 4. Prevalence of Psychiatric Disorders Stratified by Patient's Report of Chronicity

\begin{tabular}{lcc|}
\hline & \multicolumn{1}{c}{ Rates/100 (95\% Confidence Interval) } \\
\cline { 2 - 3 } $\begin{array}{l}\text { Do Chronic } \\
\text { Diagnosis }\end{array}$ & $\begin{array}{c}\text { Chronic } \\
\text { Medical Problem }\end{array}$ & Medical Problem \\
\hline $\begin{array}{l}\text { Alcohol abuse or } \\
\text { dependence }\end{array}$ & $2.5(0.9$ to 4.1$)$ & $4.4(2.4$ to 6.4$)$ \\
$\begin{array}{l}\text { Generalized anxiety } \\
\text { disorder }\end{array}$ & $3.1(1.3$ to 4.9$)$ & $3.3(1.5$ to 5.1$)$ \\
$\begin{array}{l}\text { Major depression } \\
\text { Obsessive-compulsive }\end{array}$ & $11.2(8.1$ to 14.3$)$ & $16.0(12.5$ to 19.5$)$ \\
$\quad$ disorder & $1.3(0.1$ to 2.5$)$ & $3.0(1.4$ to 4.6$)$ \\
$\begin{array}{l}\text { Panic disorder } \\
\text { Any of the above }\end{array}$ & $4.0(2.0$ to 6.0$)$ & $7.8(5.3$ to 10.3$)$ \\
& $16.7(13.0$ to 20.4$)$ & $25.8(21.7$ to 29.9$)$ \\
\hline
\end{tabular}

or dependence, $2.8 \%$; generalized anxiety disorder, not reported; major depressive disorder, $2.2 \%$; obsessivecompulsive disorder, $1.3 \%$; and panic disorder, $0.5 \%$. More recently, in the National Comorbidity Survey ${ }^{24}$ (which did not report 1-month prevalence) the 12-month prevalence rates were as follows: alcohol abuse without dependence, $2.5 \%$; alcohol dependence, $7.2 \%$; generalized anxiety disorder, $3.1 \%$; major depressive disorder, $10.3 \%$; obsessivecompulsive disorder, not reported; and panic disorder, $2.3 \%$.

\section{IMPLICATIONS FOR MENTAL HEALTH SCREENING}

In recent years, considerable effort has been devoted to improving the recognition and diagnosis of mental disorders in primary care. Several studies have examined whether feeding back to primary care physicians the results of symptom questionnaires affects the detection and treatment of mental disorders. ${ }^{22,25,26}$ We recommend the screening of all primary care patients. However, in situations where limited clinical resources make this infeasible, consideration should be given to selective screening of patients at a high risk for mental disorders. In our sample, the prevalence of mental disorders among patients presenting for follow-up appointments exceeded the comparable prevalence among patients presenting for routine physical examinations. In a similar manner, the prevalence of mental disorders among patients with a chronic medical problem exceeded the prevalence of mental disorders among patients without a chronic medical problem.

Each year large numbers of patients receive routine physical examinations. According to the National Ambulatory Medical Care Survey, general medical examinations are the most common primary reason for medical visits in office-based practice, accounting for approximately 30 million office visits each year. ${ }^{27}$ Our findings suggest that routine mental health screening at these visits may yield comparatively low rates of disorder ( $11.8 \%$ ), yet a substantial number of patients.

Research on improving the detection of mental disorders in primary care has tended to focus almost exclusively on depressive disorders and alcoholism. Our findings suggest that in addition to these conditions, panic disorder $(6.2 \%)$ is a logical candidate for the development of screening procedures. The rationale of screening for panic disorder is enhanced by the finding that in community

Table 5. Selected Studies of Prevalence of Mental Disorders Among Primary Care Patients*

\begin{tabular}{|c|c|c|c|c|c|c|}
\hline \multirow[b]{2}{*}{ Source, y } & \multicolumn{6}{|c|}{ Disorder, Rates/100 } \\
\hline & Alcohol Abuse & GAD & Major Depression & OCD & Panic Disorder & Any Disorder \\
\hline Hoeper et al, $^{10} 1979$ & & 1.6 & 5.8 & & & 26.7 \\
\hline Schulberg et al, ${ }^{5} 1985$ & 8.2 & $\ldots$ & 9.2 & 0.7 & 1.7 & \\
\hline Von Korff et al, ${ }^{6} 1987$ & 5.0 & 4.6 & 5.0 & 1.1 & 1.4 & 33.1 \\
\hline Barrett et al, 1988 & $\ldots$ & 2.9 & $2.2 \dagger$ & $\ldots$ & $\ldots$ & 26.5 \\
\hline Blacker and Clare, & & & & & & \\
\hline 1988 & 2.6 & & 4.8 & $\ldots$ & 3.2 & 35.1 \\
\hline Zinbarg et al, ${ }^{9} 1994$ & $\ldots$ & 11.9 & 7.9 & 1.2 & 4.3 & $\ldots$ \\
\hline Present study & 3.2 & 2.8 & 14.1 & 2.2 & 6.2 & 22.0 \\
\hline
\end{tabular}

*GAD indicates generalized anxiety disorder; OCD, obsessive-compulsive disorder; and ellipses, not reported.

†Includes treated major depression. 
samples, panic disorder is associated with impaired social and marital functioning, financial dependency, and suicide attempts. ${ }^{28-30}$ At the same time, the comparatively low prevalence of generalized anxiety disorder $(2.8 \%)$ and obsessive-compulsive disorder $(2.2 \%)$ may present greater challenges to successful screening programs.

\section{LIMITATIONS}

There are several limitations in the methods used to derive the prevalence estimates. The screened sample was not a random sample of primary care patients, as participants were self-selected. Furthermore, the sample that received the comprehensive diagnostic interview (the SCID-P) was not randomly selected from the screened sample. Because the prevalence estimates are based on this two-stage sampling procedure, the extent to which the subset who received the SCID-P is not representative of the screened sample will bias our estimates. A second limitation concerns the time that elapsed from screening to administering the SCID-P; for nearly half the subjects, it exceeded 14 days. A third limitation concerns the uncertain reliability and validity with which patients classified their reasons for visits and physicians classified the chronicity of the patients' medical conditions.

\section{CONCLUSIONS}

Efforts to improve the recognition and treatment of mental disorders in primary care must ultimately rely on a basic understanding of the prevalence and distribution of the major mental disorders in this practice setting. This report confirms earlier findings that mental disorders are highly prevalent in primary care. Within primary care, patients returning for follow-up care and those with chronic medical problems appear to be at an increased risk for mental disorders. Although this finding corroborates the widespread clinical impression that mental disorders are concentrated among long-term medically ill patients, it challenges the practice of selectively screening new patients and those seeking routine physical examination. This suggests that programs screening for mental disorders must not focus exclusively on new patients, but include established primary care patients as well as those with chronic medical illnesses.

\section{Accepted for publication April 26, 1995.}

This study was sponsored and supported by The Upjohn Company through its Pharmacosurveillance Unit (James A. Coleman, Director, and George B. Gross, Senior Project Manager), and its Health Care Economics and Policy Research Unit (Don Buesching, PhD, Senior Medical Sociologist).

Gerald L. Klerman, MD, was the initial principal investigator of the SDDS-PC Study until his death in April 1992. He served a prominent role in its conceptualization and design. Allen Frances, MD, and Larry Culpepper, MD, provided advice. Christina Provencal was the site project coordinator and supervised training. Robert Moore, DrPh, assisted in data collection and management; Laura Portera assisted in the data analysis; and Joy Pelayo assisted in manuscript preparation. The participating physicians were Ira G. Warshaw, MD; Margaret S. Lytton, MD; Margaret
Tryforos, MD; David P. Carter, MD; Colleen A. Cleary, MD; Arthur A. Frazzano, MD; and Gary M. Cummins, $M D$.

Reprint requests to Cornell University Medical College, Department of Psychiatry, Box 147, 525 E 68th St, New York, NY 10021 (Dr Leon).

\section{REFERENCES}

1. Goldberg DP, Blackwell P. Psychiatric illness in general practice. BMJ. 1970; 2:439-443

2. Johnstone A, Goldberg DP. Psychiatric screening in general practice: a controlled trial. Lancet. 1976;1:605-608.

3. Hesbacher PT, Rickels K, Morris RJ, Newman H, Rosenfield H. Psychiatric illness in family practice. J Clin Psychol. 1980;41:6-10.

4. Kessler LG, Cleary PD, Burke JD. Psychiatric disorders in primary care: results of a follow-up study. Arch Gen Psychiatry. 1985;42:583-587.

5. Schulberg HC, Saul M, McClelland M, et al. Assessing depression in primary medical and psychiatric practices. Arch Gen Psychiatry. 1985;42:1164-1170.

6. Von Korff M, Shapiro S, Burke JD, et al. Anxiety and depression in a primary care clinic: comparison of Diagnostic Interview Schedule, General Health Questionnaire, and practitioner assessments. Arch Gen Psychiatry. 1987;44:152-156.

7. Barrett JE, Barrett BA, Oxman TE, Gerber PD. The prevalence of psychiatric disorders in a primary care practice. Arch Gen Psychiatry. 1988:45:1100-1106.

8. Blacker CVR, Clare AW. The prevalence and treatment of depression in general practice. Psychopharmacology. 1988;95(suppl):S14-S17.

9. Zinbarg RE, Barlow DH, Liebowitz $M$, et al. The DSM-IV field trial for mixed anxiety-depression. Am J Psychiatry. 1994;151:1153-1162.

10. Hoeper EW, Nycz GR, Cleary PD, Regier DA, Goldberg ID. Estimated prevalence of RDC mental disorder in primary care. Int J Ment Health. 1979;8:6-15.

11. Clark WD. Alcoholism: blocks to diagnosis and treatment. Am J Med. 1981; 71:275-286.

12. Regier DA, Hirschfeld RM, Goodwin FK, et al. The NIMH Depression Awareness, Recognition, and Treatment Program: structure, aims, and scientific purpose. Am J Psychiatry. 1988;145:1351-1357.

13. Clinical Practice Guideline, Depression in Primary Care, II: Treatment of Major Depression. Rockville, Md: Agency for Health Care Policy and Research; 1993. AHCPR publication 9939-0551.

14. American Psychiatric Association. Diagnostic and Statistical Manual of Mental Disorders, Revised Third Edition. Washington, DC: American Psychiatric Association; 1987.

15. Endicott J, Spitzer RL. A diagnostic interview: the Schedule for Affective Disorders and Schizophrenia. Arch Gen Psychiatry. 1978;35:837-844.

16. Robins L, Helzer J, Croughan J, Ratcliff K. National Institute of Mental Health Diagnostic Interview Schedule: its history, characteristics, and validity. Arch Gen Psychiatry. 1981;38:381-389

17. Spitzer RL, Williams JBW, Gibbon M, First M. The Structured Clinical Interview for $D S M$-III-R (SCID), 1: history, rationale, and description. Arch Gen PSychiatry. 1992;49:624-629.

18. Spitzer R, Endicott J, Robins E. Research Diagnostic Criteria: rationale and reliability. Arch Gen Psychiatry. 1978;35:773-782.

19. Broadhead WE, Leon AC, Weissman MM, et al. Development and validation of the SDDS-PC screen for multiple mental disorders in primary care. Arch Fam Med. 1995:4:211-219.

20. American Psychiatric Association. Diagnostic and Statistical Manual of Mental Disorders, Fourth Edition. Washington, DC: American Psychiatric Association; 1994.

21. Kraemer HC. Evaluating Medical Tests: Objective and Quantitative Guidelines. Newbury Park, Calif: Sage Publications; 1992.

22. Magruder-Habib HK, Zung WWK. Feussner JR. Improving physicians' recognition and treatment of depression in general medical care: results from a randomized clinical trial. Med Care. 1990;28:239-250.

23. Regier DA, Boyd JH, Burke JD, et al. One-month prevalence of mental disorders in the United States: based on five Epidemiologic Catchment Area sites. Arch Gen Psychiatry. 1988;45:977-986.

24. Kessler RC, McGonagle KA, Zhao S, et al. Lifetime and 12-month prevalence of $D S M-I I-R$ psychiatric disorders in the United States: results from the National Comorbidity Survey. Arch Gen Psychiatry. 1994;51:8-19.

25. Shapiro S, German PS, Skinner EA, et al. An experiment to change detection and management of mental morbidity in primary care. Med Care. 1987;25: . 327-339.

26. Zung WWK, Magill M, Moore JT, George DT. Recognition and treatment of depression in a family medicine practice. $J$ Clin Psychiatry. 1983:44:3-6.

27. Schappert SM. National Ambulatory Medical Care Survey: 1990 summary. Advance Data. 1992:213.

28. Klerman GL, Weissman MM, Ouellette R, Johnson J, Greenwald S. Panic attacks in the community: social morbidity and health care utilization. JAMA. 1991:265:742-746.

29. Weissman MM, Klerman GL, Markowitz JS, Ouellette R. Suicidal ideation and suicide attempts in panic disorder and panic attacks. N Engl J Med. 1989;321: 1209-1214.

30. Leon AC, Klerman GL, Weissman M, Fyer AJ, Johnson J. Evaluating the diagnostic criteria for panic disorder: measures of social morbidity as criteria. Soc Psychiatry Psychiatr Epidemiol. 1992;27:180-184. 